\title{
Functional capacity, physical activity, and quality of life in hypoxemic patients with chronic obstructive pulmonary disease
}

This article was published in the following Dove Press journal:

International Journal of COPD

26 February 2015

Number of times this article has been viewed

\author{
Melda Saglam' \\ Naciye Vardar-Yagli' \\ Sema Savci \\ Deniz Inal-Ince' \\ Ebru Calik-Kutukcu' \\ Hülya Arikan' \\ Lutfi Coplu ${ }^{3}$ \\ 'Department of Physiotherapy \\ and Rehabilitation, Faculty \\ of Health Sciences, Hacettepe \\ University, Ankara, Turkey; ${ }^{2}$ School \\ of Physiotherapy and Rehabilitation, \\ Dokuz Eylul University, Izmir, Turkey; \\ ${ }^{3}$ Department of Chest Medicine, \\ Faculty of Medicine, Hacettepe \\ University, Ankara, Turkey
}

Background: The risk of hypoxemia increases with the progression of chronic obstructive pulmonary disease (COPD) and the deterioration of pulmonary function. The aim of this study was to compare functional capacity, physical activity, and quality of life in hypoxemic and non-hypoxemic patients with COPD.

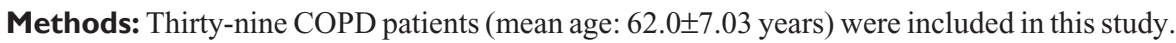
Arterial blood gas tensions were measured, and patients were divided into two groups according to oxygen partial pressure $\left(\mathrm{PaO}_{2}\right)$, the hypoxemic $\mathrm{COPD}\left(\mathrm{PaO}_{2}<60 \mathrm{mmHg}\right)(\mathrm{n}=18)$, and the control $\left(\mathrm{PaO}_{2} \geq 60 \mathrm{mmHg}\right)(\mathrm{n}=21)$ groups. Functional exercise capacity was evaluated using the 6-minute walk test (6MWT). Oxygen saturation, dyspnea, and fatigue perception were measured before and after the 6MWT. Physical activity was assessed using the International Physical Activity Questionnaire (IPAQ) and an accelerometer. Quality of life was assessed using the St George's Respiratory Questionnaire (SGRQ).

Results: The number of emergency visits and hospitalizations were higher in hypoxemic patients $(P<0.05)$. Lung function parameters, 6MWT distance, exercise oxygen saturation, IPAQ total score, and energy expenditure during daily life were significantly lower, but percentage of maximum heart rate reached during the 6MWT was significantly higher, in hypoxemic COPD patients than in controls $(P<0.05)$.

Conclusion: Hypoxemia has a profound effect on functional capacity and physical activity in patients with COPD.

Keywords: COPD, hypoxemia, 6-minute walk test

\section{Introduction}

Chronic obstructive pulmonary disease (COPD) is one of the leading diseases causing mortality and morbidity. ${ }^{1}$ The progression of disease and deterioration in pulmonary function increases alveolar hypoxia and ultimately the risk of hypoxemia. ${ }^{2}$ The greatest contributing factor to hypoxemia is ventilation/perfusion mismatch resulting from progressive airway limitation and emphysematous destruction of the pulmonary capillary bed. Dynamic hyperinflation, total lung capacity, cardiovascular factors such as oxygen consumption and cardiac output, nutritional status, and female sex also contribute to the risk of hypoxemia..$^{3-6}$

Hypoxemia and tissue hypoxia cause systemic imbalance and inflammation. Protein synthesis is reduced and muscle cell structure is altered in hypoxemia. Complications and extrapulmonary comorbidities including cardiovascular disorders, pulmonary hypertension, polycythemia, neurocognitive dysfunction, impairment of life quality, lower exercise tolerance, and skeletal muscle weakness are common, and the risk of death is increased with the presence of hypoxemia in COPD..$^{7-9}$
Correspondence: Melda Saglam and Rehabilitation, Faculty of Health Sciences, Hacettepe University, 06100, Samanpazari, Ankara, Turkey Tel +90 3I2 3051577 ext 123 Fax +90312305 2012

Email msaglam@hacettepe.edu.tr 
Hypoxemia leads to the conversion of aerobic metabolism to anaerobic metabolism in low levels of physical activity in COPD. ${ }^{10}$ Physical inactivity is considered an important marker of advanced COPD. Reduced skeletal muscle oxidative capacity can have a negative effect on exercise capacity and physical activity in COPD patients. ${ }^{11}$

Few studies have examined hypoxemia and related factors including exercise capacity, muscle function, and quality of life. ${ }^{6,12,13}$ To our knowledge, no published study has examined whether quality of life, functional capacity, and physical activity change between hypoxemic and non-hypoxemic COPD patients. Identifying these factors can guide clinicians in the follow-up of COPD patients. The aim of this study was to compare functional capacity, physical activity, and quality of life in hypoxemic and non-hypoxemic patients with COPD.

\section{Methods}

This cross-sectional, observational study included 39 clinically stable COPD (34 male and five female) patients between the ages of 41 and 78 years with a mean forced expiratory volume in 1 second $\left(\mathrm{FEV}_{1}\right)$ of $50.64 \% \pm 23.17 \%$. Diagnosis of disease and classification of disease severity were established in line with the Global initiative for chronic Obstructive Lung Disease (GOLD) criteria. Patients who were not able to walk or perform the 6-minute walk test (6MWT), patients who were not able to cooperate in pulmonary function testing, patients with oral corticosteroid use for at least 6 weeks, and patients with heart disease and acute exacerbation were not included in the study. According to arterial blood gas analysis, patients with oxygen partial pressure $\left(\mathrm{PaO}_{2}\right)$ of $<60 \mathrm{mmHg}$ were assigned to the hypoxemic COPD group and patients with $\mathrm{PaO}_{2} \geq 60 \mathrm{mmHg}$ were assigned to the non-hypoxemic control group. The hypoxemic group consisted of 18 patients and the non-hypoxemic control group consisted of 21 patients. The study was approved by the Ethics Committee of Hacettepe University, Ankara, Turkey, and signed informed consent forms were obtained from each patient before the study.

Physical, physiological, and sociodemographic data of the patients were recorded. Body mass index was calculated by the following formula: body weight $/ \mathrm{height}^{2}\left(\mathrm{~kg} / \mathrm{m}^{2}\right) .{ }^{14} \mathrm{The}$ patients' smoking history was recorded as pack-years.

The lung function test was performed in a seated position using a Spirolab III spirometer (Medical International Research, Rome, Italy) consistent with American Thoracic Society (ATS)/European Respiratory Society (ERS) guidelines. Forced vital capacity (FVC), $\mathrm{FEV}_{1}, \mathrm{FEV}_{1} / \mathrm{FVC}$ rate, peak expiratory flow, and forced expiratory flow between $25 \%$ and $75 \%$ of $\mathrm{FVC}\left(\mathrm{FEF}_{25 \%-75 \%}\right)$ were recorded. Lung function test parameters were expressed as percentage of the predicted values for age, height, body weight, and sex..$^{15,16}$

Resting arterial blood gas analysis was performed in environmental air, with radial arterial blood collected to analyze the concentration of hydrogen ions $(\mathrm{pH}), \mathrm{PaO}_{2}$, partial carbon dioxide pressure, and oxygen saturation. We used the AVL Compact I (AVL Medical Instruments A.G., Schaffhausen, Switzerland) blood gas analyzer to adjust these variables. The alveolar-arterial oxygen gradient $\left(\mathrm{P}[\mathrm{A}-\mathrm{a}] \mathrm{O}_{2}\right)$ was calculated using the measured $\mathrm{PaO}_{2}$ and partial carbon dioxide pressure assuming a standard respiratory exchange ratio of 0.8 .

The 6MWT was performed according to ATS guidelines. ${ }^{17}$ Patients were asked to walk quickly along a $30 \mathrm{~m}$ level corridor for 6 minutes, and the total distance walked was recorded as meters. The test was carried out twice with a 30-minute interval. The best value of the two tests was used for statistical analysis. Heart rate and oxygen saturation were recorded during the 6MWT using a pulse oximeter (KPTS-01, Seoul, South Korea). Fatigue and dyspnea perception were assessed using the modified Borg rating of perceived exertion scale scores before and after the test. ${ }^{18}$

Physical activity was determined using the selfadministered short form of the International Physical Activity Questionnaire (IPAQ).${ }^{19}$ The IPAQ requires respondents to estimate time spent in various levels of physical activity during the previous week. Scores for walking and moderate and vigorous activities are calculated as durations and frequencies multiplied by known metabolic equivalents per activity. The results for all activity-based items are summed for the total physical activity score. An item regarding time spent sitting is not included in the total physical activity score and is a separate score expressed as minutes. ${ }^{20}$

Daily energy expenditure was measured for 4 consecutive days ( 2 weekdays and 2 weekend days) using the Caltrac accelerometer (Muscle Dynamics Fitness Network, Torrance, CA, USA). Patients were asked to continue their typical daily physical activities. For data analysis, the average energy expenditure during the 4 days was used.

The St George's Respiratory Questionnaire (SGRQ) was used to assess quality of life. The SGRQ has 76 items that are divided into three sections including symptoms, activity, and impacts. Scores for each section and the total score range from $0-100$, with high scores indicating poor health status. ${ }^{21}$

\section{Statistical analysis}

Statistical analysis was performed using the Statistical Package for the Social Sciences (SPSS) version 18.0 software 
(SPSS Inc., Chicago, IL, USA). We used the Shapiro-Wilk test to test the normal distribution of the arterial blood gas analysis, spirometry, the 6MWT, physical activity, and the SGRQ. Comparison between hypoxemic and non-hypoxemic COPD was performed using the Mann-Whitney $U$ test. ChiSquare test was used for IPAQ categorical classification. Kruskal-Wallis rank sum test with post hoc analysis was used to compare normal and higher gradient levels of the hypoxemic group to the non-hypoxemic group. The level of statistical significance was set at $P<0.05$ for all analyses. ${ }^{22}$

\section{Results}

Thirty-nine patients entered the study (21 non-hypoxemic, 18 hypoxemic), and none of them were excluded during the measurements. Five patients in the hypoxemic COPD group were prescribed supplementary oxygen therapy. Patients' characteristics are shown in Table 1. There were no significant differences in age, sex, height, weight, body mass index, disease duration, and smoking history between the two groups $(P>0.05)$.

According to GOLD phenotypes, seven (33\%) patients were in group A, ten (47.6\%) patients were in group B, three $(14.3 \%)$ patients were in group $\mathrm{C}$, and one (4.8\%) patient was in group D classification level among the non-hypoxemic patients. In the hypoxemic patient group, one (5.6\%) patient was in group A, five (27.8\%) patients were in group B, and 12 (66.7\%) patients were in group D classification level. There was a significant difference between the groups when classified by GOLD ABCD index, and patients in the hypoxemic group were more likely to be in higher-risk GOLD classes $(P<0.05)$. Higher GOLD severity classification was significantly correlated with hypoxemia $(r=-0.645, P<0.001)$. GOLD ABCD classification was correlated with 6MWT distance $(r=-0.625, P<0.001)$, IPAQ total score $(r=-0.355$, $P=0.03)$, IPAQ walking score $(r=-0.373, P=0.02)$, daily energy expenditure $(r=-0.468, P=0.003)$, SGRQ total score $(r=0.565, P<0.001)$, SGRQ symptom subdomain $(r=0.560$, $P<0.001)$, SGRQ activity subdomain $(r=0.495, P=0.002)$, and SGRQ impact subdomain $(r=0.527, P=0.001)$.

The numbers of emergency visits and hospitalizations were higher in the hypoxemic patients $(P<0.05)$. Lung function test findings were significantly lower in the hypoxemic patients $(P<0.05)$ (Table 1$)$.

Functional capacity, physical activity, and quality of life variables are shown in Table 2. The 6MWT distance and exercise oxygen saturation were significantly lower and

Table I Physical and demographic variables in hypoxemic and non-hypoxemic patients with COPD

\begin{tabular}{|c|c|c|c|}
\hline Variables & Hypoxemic COPD & Non-hypoxemic COPD & $P$-value \\
\hline Age (years) & $62.83 \pm 7.37$ & $59.95 \pm 8.83$ & 0.335 \\
\hline Sex (male/female) & $16 / 2$ & $18 / 3$ & 0.768 \\
\hline Height (cm) & $167.59 \pm 6.40$ & $167 \pm 5.59$ & 0.839 \\
\hline Weight (kg) & $71.00 \pm 13.4 \mid$ & $75.44 \pm|2.9|$ & 0.322 \\
\hline Body mass index $\left(\mathrm{kg} / \mathrm{m}^{2}\right)$ & $25.88 \pm 3.60$ & $27.3 I \pm 5.24$ & 0.338 \\
\hline Time from diagnosis (years) & $6.89 \pm 4.70$ & $8.61 \pm 7.56$ & 0.791 \\
\hline Smoking (pack-years) & $48.14 \pm 23.88$ & $42.63 \pm 29.51$ & 0.553 \\
\hline Number of doctor visits ( $n /$ year) & $3.56 \pm 3.26$ & $2.67 \pm 1.53$ & 0.460 \\
\hline Number of emergency visits (n/year) & $1.06 \pm 1.83$ & $0.48 \pm 2.18$ & $0.04 *$ \\
\hline Number of hospitalizations (n/year) & $0.67 \pm 0.91$ & $0.05 \pm 0.21$ & $0.03^{*}$ \\
\hline $\mathrm{pH}$ & $7.4 I \pm 0.04$ & $7.43 \pm 0.03$ & 0.06 \\
\hline $\mathrm{PaO}_{2}(\mathrm{mmHg})$ & $55.36 \pm 4.01$ & $77.80 \pm 5.93$ & - \\
\hline $\mathrm{PaCO}_{2}(\mathrm{mmHg})$ & $43.26 \pm 7.90$ & $35.68 \pm 3.02$ & $<0.00 I^{* *}$ \\
\hline $\mathrm{SaO}_{2}(\%)$ & $87.52 \pm 5.56$ & $95.90 \pm 1.19$ & - \\
\hline $\mathrm{P}(\mathrm{A}-\mathrm{a}) \mathrm{O}_{2}(\mathrm{mmHg})$ & $22.04 \pm 8.66$ & $9.06 \pm 5.78$ & $<0.001 * *$ \\
\hline $\mathrm{HCO}_{3}(\mathrm{mEq} / \mathrm{L})$ & $26.70 \pm 4.21$ & $23.20 \pm 2.61$ & $0.00 I^{* *}$ \\
\hline $\mathrm{FEV}_{1}(\%)$ & $36.67 \pm|2.9|$ & $62.62 \pm 23.50$ & $<0.00 I^{* *}$ \\
\hline FVC (\%) & $54.39 \pm 15.27$ & $78.38 \pm 19.00$ & $<0.00 I^{* * *}$ \\
\hline $\mathrm{FEV}_{6}(\%)$ & $52.00 \pm 13.49$ & $80.13 \pm 18.80$ & $<0.001 * *$ \\
\hline $\mathrm{FEV}_{1} / \mathrm{FVC}$ & $56.53 \pm 13.26$ & $64.11 \pm 13.75$ & 0.06 \\
\hline PEF (\%) & $45.06 \pm 15.24$ & $65.90 \pm 28.87$ & $0.03 *$ \\
\hline $\mathrm{FEF}_{25 \%-75 \%}(\%)$ & $|8.1| \pm 8.07$ & $38.10 \pm 21.52$ & $<0.001^{* *}$ \\
\hline
\end{tabular}

Notes: Values are expressed as mean \pm standard deviation. $* P<0.05 ; * * P<0.001$

Abbreviations: COPD, chronic obstructive pulmonary disease; $\mathrm{PaO}_{2}$, oxygen partial pressure; $\mathrm{PaCO}_{2}$, carbon dioxide partial pressure; SaO , oxygen saturation; $\mathrm{P}(\mathrm{A}-\mathrm{a}) \mathrm{O}_{2}$, alveolar-arterial oxygen gradient; $\mathrm{HCO}_{3}$, hydrogen bicarbonate; $\mathrm{FEV}_{1}$, forced expiratory volume in I second; FVC, forced vital capacity; FEV ${ }_{6}$, forced expiratory volume in 6 seconds; PEF, peak expiratory flow; $\mathrm{FEF}_{25 \%-75 \%}$, forced expiratory flow between $25 \%$ and $75 \%$ of FVC. 
Table 2 Functional capacity, physical activity, and quality of life in hypoxemic and non-hypoxemic patients with COPD

\begin{tabular}{llll}
\hline Variables & Hypoxemic COPD & Non-hypoxemic COPD & P-value \\
\hline 6MWT distance $(m)$ & $445.29 \pm 92.96$ & $547.58 \pm 87.24$ & $0.002^{*}$ \\
\%HRmax & $78.84 \pm 7.49$ & $68.79 \pm 11.66$ & $0.007^{*}$ \\
Borg-dyspnea (0-10) & $3.72 \pm 3.06$ & $2.19 \pm 2.79$ & 0.073 \\
Borg-fatigue (0-I0) & $2.64 \pm 2.54$ & $2.64 \pm 2.33$ & 0.989 \\
SPO $(\%)$ & $85.61 \pm 8.54$ & $95.76 \pm 3.02$ & - \\
IPAQ total score (MET-min/week) & $1,012.44 \pm 890.93$ & $2,844.02 \pm 3,164.01$ & $0.023^{*}$ \\
IPAQ walking score (MET-min/week) & $828.91 \pm 671.58$ & $1,512.55 \pm 2,101.16$ & $0.58 I$ \\
IPAQ moderate score (MET-min/week) & $178.82 \pm 395.82$ & $552.38 \pm 1,018.18$ & 0.128 \\
IPAQ vigorous score (MET-min/week) & $4.71 \pm 19.40$ & $779.05 \pm 2,400.65$ & 0.467 \\
IPAQ sitting score (min) & $608.24 \pm 240.21$ & $532.86 \pm 202.56$ & 0.243 \\
Energy expenditure (cals/day) & $412.33 \pm 277.62$ & $599.66 \pm 221.66$ & $0.04 *$ \\
SGRQ symptom score (0-I00) & $63.51 \pm 29.98$ & $52.72 \pm 23.56$ & 0.196 \\
SGRQ activity score (0-100) & $62.87 \pm 26.50$ & $52.46 \pm 23.77$ & 0.186 \\
SGRQ impact score (0-100) & $45.75 \pm 21.75$ & $37.56 \pm 19.33$ & 0.167 \\
SGRQ total score (0-I00) & $53.96 \pm 22.55$ & $44.73 \pm 19.64$ & 0.158 \\
\hline Notes Vals are & & & \\
\hline
\end{tabular}

Notes: Values are expressed as mean \pm standard deviation. $* P<0.05$.

Abbreviations: COPD, chronic obstructive pulmonary disease; 6MWT, 6-minute walk test; \%HRmax, percentage of maximal heart rate; $\mathrm{SpO}_{2}$, oxygen saturation with pulse oximeter; MET, metabolic equivalent; IPAQ, International Physical Activity Questionnaire; SGRQ, St George's Respiratory Questionnaire.

percentage of maximum heart rate reached during the test was significantly higher in hypoxemic COPD patients compared to the non-hypoxemic group $(P<0.05)$ (Table 2).

The IPAQ total score and energy expenditure during daily life were significantly lower in hypoxemic patients $(P<0.05)$ (Table 2). Six (35\%) patients were inactive, ten (59\%) patients were minimally active, and one patient $(6 \%)$ was sufficiently active in the hypoxemic group, whereas two (9\%) patients were inactive, 14 (67\%) patients were minimally active, and five patients (24\%) were sufficiently active among the non-hypoxemic patients according to IPAQ categorical classification $(P<0.05)$. No significant difference in time spent sedentarily, measured using the sitting time score of IPAQ, was observed between the two groups $(P>0.05)$ (Table 2).

There were no significant differences in SGRQ total and subscale scores between the hypoxemic and the nonhypoxemic patients with COPD $(P>0.05)$ (Table 2$)$.

According to $\mathrm{P}(\mathrm{A}-\mathrm{a}) \mathrm{O}_{2}$ gradient, eleven (61.1\%) patients had a higher gradient level assuming low ventilation/ perfusion ratio and seven (38.9\%) patients had a normal $\mathrm{P}(\mathrm{A}-\mathrm{a}) \mathrm{O}_{2}$ level due to hypoventilation in the hypoxemic COPD group. All patients had a normal gradient in the nonhypoxemic group. Post hoc analysis revealed no differences when the normal and higher gradient hypoxemic groups were compared to the non-hypoxemic group $(P>0.05)$.

\section{Discussion}

The current study has two main findings: 1) more frequent emergency visits and hospitalization and 2) reduced lung function, functional exercise capacity, and physical activity level in daily life in hypoxemic patients with COPD. Higher GOLD severity classification was significantly correlated with hypoxemia in patients with COPD.

Emergency department visits and hospitalizations are an important risk of disease progression and are the predictors of acute exacerbations in COPD. They are related with morbidity, mortality, worsened health status, and impaired lung function. ${ }^{23,24}$ In this study, we showed that the presence of hypoxemia may have an effect on number of emergency visits and hospitalizations. Implementation of a comprehensive self-management strategy, especially including oxygen therapy, may result in a lower hospitalization rate and fewer emergency department visits. COPD patients who experienced exacerbations and a higher hospitalization rate have shown markedly lower skeletal muscle strength, 6-minute walk distance, physical activity, and quality of life. ${ }^{25}$

The decline of $\mathrm{PaO}_{2}$ was in line with a decrease in $\mathrm{FEV}_{1}$, FVC, peak expiratory flow, and $\mathrm{FEF}_{25 \%-75 \%}$ in COPD patients in our study. Airway obstruction reduces ventilation and causes ventilation/perfusion mismatch. One study showed that airflow limitation increased progressively with arterial blood gas disturbances. ${ }^{26} \mathrm{~A}$ multicenter 3-year follow up study also demonstrated that lower levels of $\mathrm{PaO}_{2}$ were associated with a higher functional residual capacity and total lung capacity that reflects the degree of hyperinflation. ${ }^{27}$

Functional exercise capacity measured using the 6MWT was markedly reduced in our hypoxemic patients. Romer et al showed that the reduction in $\mathrm{PaO}_{2}$ negatively impacted 
functional capacity and fatigability in healthy individuals with skeletal muscle dysfunction. ${ }^{28}$ Exercise performance depends on aerobic metabolism and oxidative capacity. Hypoxemia has been linked to a more glycolytic muscle profile and ultimately with the decline in 6MWT. ${ }^{12}$ Our hypoxemic patients also experienced more severe oxygen desaturation during the 6MWT. Oxygen desaturation during the 6MWT occurs due to the imbalance between oxygen supply and demand during exercise associated with skeletal muscle dysfunction and hemodynamic and respiratory problems in COPD patients. ${ }^{29}$ Arterial hypoxemia is associated with poor oxygen transport to the muscles, increasing oxygen desaturation during exercise. This desaturation during exercise increases the risk of poor prognosis. ${ }^{30}$

We found that patients with hypoxemic COPD were less physically active during their daily life measured using both subjective and objective methods. To our knowledge, this was the first study that reported the physical activity level in hypoxemic patients with COPD. Like exercise performance, physical activity also predominantly depends on the aerobic capacity. ${ }^{31}$ It appears that hypoxemia has a significant impact on physical activity in COPD. Endurance training is known to promote more aerobic muscle performance in COPD, with increases in number of type 1 muscle fibers, mitochondrial density, oxidative enzyme activity, and capillarization. ${ }^{32}$ Exercise may facilitate gas exchange in patients with COPD by improving the ventilation/perfusion ratio. Supplemental use of noninvasive ventilation, oxygen therapy, and heliox during exercise to enhance the physiological benefits of exercise is not well established and is not routine in clinical practice. ${ }^{33}$

Hypoxemia and acidosis affect sympathetic activation and chemoreflex control of heart rate responses. ${ }^{34}$ Studies showed a relationship between higher resting heart rate and low levels of $\mathrm{PaO}_{2}$. The presence of hypoxemia increased resting heart rate $49 \%$ per ten beats per minute. ${ }^{35,36}$ In accordance with the literature, the hypoxemic patients in our study also exhibited elevated heart rate responses during exercise testing.

Most related studies have demonstrated a significant impairment of quality of life in hypoxemic COPD patients compared to a control group..$^{13,37}$ As was the case in our study, however, a few studies showed no relationship between $\mathrm{PaO}_{2}$ and quality of life scores. ${ }^{38,39}$ A possible explanation for these findings is that few patients used supplementary oxygen in our hypoxemic group; therefore, there was no improvement in health status resulting from long-term oxygen therapy.

We did not find any differences between hypoxemic patients with normal and higher $\mathrm{P}(\mathrm{A}-\mathrm{a}) \mathrm{O}_{2}$ gradient levels compared to the non-hypoxemic group. However, there were very few patients in each group. Further research with larger patient numbers is needed to investigate the effect different causes of hypoxemia have on functional parameters.

Our study had limitations which must be taken into consideration. The small sample size may not allow for the determination of the relationship between hypoxemia and quality of life in COPD. Measurement of static lung volume and diffusing capacity of the lungs for carbon monoxide can yield more information about the relationship between hypoxemia and lung function. However, we showed for the first time in the literature that functional capacity, physical activity, and exercise heart rate change between hypoxemic and non-hypoxemic COPD patients.

\section{Conclusion}

We can conclude that hypoxemia is an important variable to detect reductions in lung function, functional exercise capacity, and physical activity level in patients with COPD. Arterial hypoxemia and lung function deterioration have a main negative impact of limitation of exercise capacity in COPD. Further study is needed to investigate the effects of long-term oxygen therapy on functional capacity and physical activity in patients with hypoxemic COPD.

\section{Disclosure}

The authors report no conflicts of interest in this work.

\section{References}

1. Murray CJ, Lopez AD. Alternative projections of mortality and disability by cause 1990-2020: Global Burden of Disease Study. Lancet. 1997;349:1498-1504

2. Rabe KF, Hurd S, Anzueto A, et al; Global Initiative for Chronic Obstructive Lung Disease. Global strategy for the diagnosis, management, and prevention of chronic obstructive pulmonary disease: GOLD executive summary. Am J Respir Crit Care Med. 2007;176:532-555.

3. Sandek K, Bratel T, Lagerstrand L, Rosell H. Relationship between lung function, ventilation-perfusion inequality and extent of emphysema as assessed by high-resolution computed tomography. Respir Med. 2002;96:934-943.

4. Barberà JA, Roca J, Ferrer A, et al. Mechanisms of worsening gas exchange during acute exacerbations of chronic obstructive pulmonary disease. Eur Respir J. 1997;10:1285-1291.

5. Saure EW, Eagan TM, Jensen RL, et al. Explained variance for blood gases in a population with COPD. Clin Respir J. 2012;6:72-80.

6. Kim DK, Jacobson FL, Washko GR, et al. Clinical and radiographic correlates of hypoxemia and oxygen therapy in the COPDGene study. Respir Med. 2011;105:1211-1221.

7. Macnee W, Maclay J, McAllister D. Cardiovascular injury and repair in chronic obstructive pulmonary disease. Proc Am Thorac Soc. 2008;5:824-833.

8. Kent BD, Mitchell PD, McNicholas WT. Hypoxemia in patients with COPD: cause, effects, and disease progression. Int J Chron Obstruct Pulmon Dis. 2011;6:199-208.

9. Kim HC, Mofarrahi M, Hussain SN. Skeletal muscle dysfunction in patients with chronic obstructive pulmonary disease. Int J Chron Obstruct Pulmon Dis. 2008;3:637-658. 
10. Bigard AX, Sanchez H, Birot O, Serrurier B. Myosin heavy chain composition of skeletal muscles in young rats growing under hypobaric hypoxia conditions. J Appl Physiol (1985). 2000;88:479-486.

11. Maltais F, Jobin J, Sullivan MJ, et al. Metabolic and hemodynamic responses of lower limb during exercise in patients with COPD. J Appl Physiol (1985). 1998;84:1573-1580.

12. Leite Rodrigues S, Melo e Silva CA, Ferreira Amorim C, Lima T, Almeida Ribeiro F, de Assis Viegas CA. Correlation between mild hypoxaemia and limb skeletal muscle function in chronic obstructive pulmonary disease - pilot study. Rev Port Pneumol. 2008;14:769-785. English, Portuguese.

13. Okubadejo AA, Jones PW, Wedzicha JA. Quality of life in patients with chronic obstructive pulmonary disease and severe hypoxaemia. Thorax. 1996;51:44-47.

14. Jette DU, Manago D, Medved E, Nickerson A, Warzycha T, Bourgeois MC. The disablement process in patients with pulmonary disease. Phys Ther. 1997;77:385-394.

15. Pellegrino R, Viegi G, Brusasco V, et al. Interpretative strategies for lung function tests. Eur Respir J. 2005;26:948-968.

16. Miller MR, Crapo R, Hankinson J, et al; ATS/ERS Task Force. General considerations for lung function testing. Eur Respir J. 2005;26:153-161

17. ATS Committee on Proficiency Standards for Clinical Pulmonary Function Laboratories. ATS statement: guidelines for the six-minute walk test. Am J Respir Crit Care Med. 2002;166:111-117.

18. Wilson RC, Jones PW. A comparison of the visual analogue scale and modified Borg scale for the measurement of dyspnoea during exercise. Clin Sci (Lond). 1989;76(3):277-282.

19. Craig CL, Marshall AL, Sjöström M, et al. International physical activity questionnaire: 12-country reliability and validity. Med Sci Sports Exerc. 2003;35:1381-1395.

20. Saglam M, Arikan H, Savci S, et al. International physical activity questionnaire: reliability and validity of the Turkish version. Percept Mot Skills. 2010;111:278-284.

21. Jones PW, Quirk FH, Baveystock CM. The St George's Respiratory Questionnaire. Respir Med. 1991;85 Suppl B:25-31.

22. Green SB, Salkind NJ. Using SPSS for Windows and Macintosh: Analyzing and Understanding Data. 6th ed. NJ: Pearson/Prentice Hall: Upper Saddle River, New Jersey, USA; 2003.

23. Garcia-Aymerich J, Farrero E, Félez MA, Izquierdo J, Marrades RM, Antó JM; Estudi del Factors de Risc d'Agudització de la MPOC investigators. Risk factors of readmission to hospital for a COPD exacerbation: a prospective study. Thorax. 2003;58:100-105.

24. Fan VS, Curtis JR, Tu SP, McDonell MB, Fihn SD; Ambulatory Care Quality Improvement Project Investigators. Using quality of life to predict hospitalization and mortality in patients with obstructive lung diseases. Chest. 2002;122:429-436.

25. Beekman E, Mesters I, Hendriks EJ, et al. Exacerbations in patients with chronic obstructive pulmonary disease receiving physical therapy: a cohort-nested randomised controlled trial. BMC Pulm Med. 2014;14:71
26. Rodríguez-Roisin R, Drakulovic M, Rodríguez DA, Roca J, Barberà JA, Wagner PD. Ventilation-perfusion imbalance and chronic obstructive pulmonary disease staging severity. J Appl Physiol (1985). 2009; 106:1902-1908.

27. Saure EW, Eagan TM, Jensen RL, et al. Predictors for $\mathrm{PaO}_{2}$ and hypoxemic respiratory failure in COPD-A three-year follow-up. COPD. 2014;11:531-538

28. Romer LM, Haverkamp HC, Amann M, Lovering AT, Pegelow DF, Dempsey JA. Effect of acute severe hypoxia on peripheral fatigue and endurance capacity in healthy humans. Am J Physiol Regul Integr Comp Physiol. 2007;292:R598-R606.

29. Andrianopoulos V, Franssen FM, Peeters JP, et al. Exercise-induced oxygen desaturation in COPD patients without resting hypoxemia. Respir Physiol Neurobiol. 2014;190:40-46.

30. Amann M, Regan MS, Kobitary M, et al. Impact of pulmonary system limitations on locomotor muscle fatigue in patients with COPD. Am J Physiol Regul Integr Comp Physiol. 2010;299:R314-R324.

31. Gosselin N, Lambert K, Poulain M, Martin A, Préfaut C, Varray A. Endurance training improves skeletal muscle electrical activity in active COPD patients. Muscle Nerve. 2003;28:744-753.

32. Casaburi R, Porszasz J, Burns MR, Carithers ER, Chang RS, Cooper CB. Physiologic benefits of exercise training in rehabilitation of patients with severe chronic obstructive pulmonary disease. Am J Respir Crit Care Med. 1997; 155:1541-1551.

33. Moga AM, de Marchie M, Saey D, Spahija J. Mechanisms of nonpharmacologic adjunct therapies used during exercise in COPD. Respir Med. 2012;106:614-626.

34. Ba A, Delliaux S, Bregeon F, Levy S, Jammes Y. Post-exercise heart rate recovery in healthy, obeses, and COPD subjects: relationships with blood lactic acid and $\mathrm{PaO} 2$ levels. Clin Res Cardiol. 2009;98:52-58.

35. Miyamoto K, Nishimura M, Akiyama Y, Yamamoto H, Kishi F, Kawakami Y. Augmented heart rate response to hypoxia in patients with chronic obstructive pulmonary disease. Am Rev Respir Dis. 1992;145:1384-1388

36. Roca M, Mitu F, Roca IC, Mihăescu T. Heart rate variations in chronic obstructive pulmonary disease. Rev Med Chir Soc Med Nat Iasi. 2013;117:616-622.

37. Stavem K, Erikssen J, Boe J. Health-related quality of life is associated with arterial $\mathrm{P}(\mathrm{O} 2)$ in chronic obstructive pulmonary disease. Respir Med. 2000;94:772-777.

38. Prigatano GP, Wright EC, Levin D. Quality of life and its predictors in patients with mild hypoxemia and chronic obstructive pulmonary disease. Arch Intern Med. 1984;144:1613-1619.

39. McSweeny AJ, Grant I, Heaton RK, Adams KM, Timms RM. Life quality of patients with chronic obstructive pulmonary disease. Arch Intern Med. 1982;142:473-478.
International Journal of COPD

\section{Publish your work in this journal}

The International Journal of COPD is an international, peer-reviewed journal of therapeutics and pharmacology focusing on concise rapid reporting of clinical studies and reviews in COPD. Special focus is given to the pathophysiological processes underlying the disease, intervention programs, patient focused education, and self management protocols.

\section{Dovepress}

This journal is indexed on PubMed Central, MedLine and CAS. The manuscript management system is completely online and includes a very quick and fair peer-review system, which is all easy to use. Visit http://www.dovepress.com/testimonials.php to read real quotes from published authors. 